\title{
The National Map-Elevation
}

\section{National Elevation Dataset}

The National Elevation Dataset (NED) is the primary elevation data product produced and distributed by the USGS. The NED provides seamless raster elevation data of the conterminous United States, Alaska, Hawaii, and the island territories. The NED is derived from diverse source data sets that are processed to a specification with a consistent resolution, coordinate system, elevation units, and horizontal and vertical datums. The NED is the logical result of the maturation of the long-standing USGS elevation program, which for many years concentrated on production of topographic map quadrangle-based digital elevation models. The NED serves as the elevation layer of The National Map, and provides basic elevation information for earth science studies and mapping applications in the United States.

The NED is a multi-resolution dataset that is updated bimonthly to integrate newly available, improved elevation source data. NED data are available nationally at grid spacings of 1 arc-second (approximately 30 meters) for the conterminous United States, and at 1/3 and 1/9 arc-seconds (approximately 10 and 3 meters, respectively) for parts of the United States. Most of the NED for Alaska is available at 2-arc-second (about 60 meters) grid spacing, where only lower resolution source data exist. Part of Alaska is available at the $1 / 3$-arc-second resolution, and plans are in development for a significant upgrade in elevation data coverage of the State over the next 5 years. Specifications for the NED include the following:

- Coordinate system: Geographic (decimal degrees of

latitude and longitude),

- Horizontal datum: North American Datum of 1983 (NAD 83),

- Vertical datum: North American Vertical
Datum of 1988 (NAVD 88) over the conterminous United States and varies in other areas, and

- Elevation units: Decimal meters.

\section{Spatially Referenced Metadata}

NED data are documented in compliance with the Federal Geographic Data Committee's Content Standard for Digital Geospatial Metadata. The footprint of each source dataset is retained during NED assembly to provide a spatial context. The native attributes of each source dataset, such as the original resolution and production method, as well as a description of the assembly process, are linked to these footprints. The set of footprints provides spatially referenced metadata as an attributed geospatial data layer. Through the metadata, information regarding the source data is available for any area of the NED. For example, a user can access the spatially referenced metadata to evaluate the source data over a project area to determine applicability of the NED for a specific use.

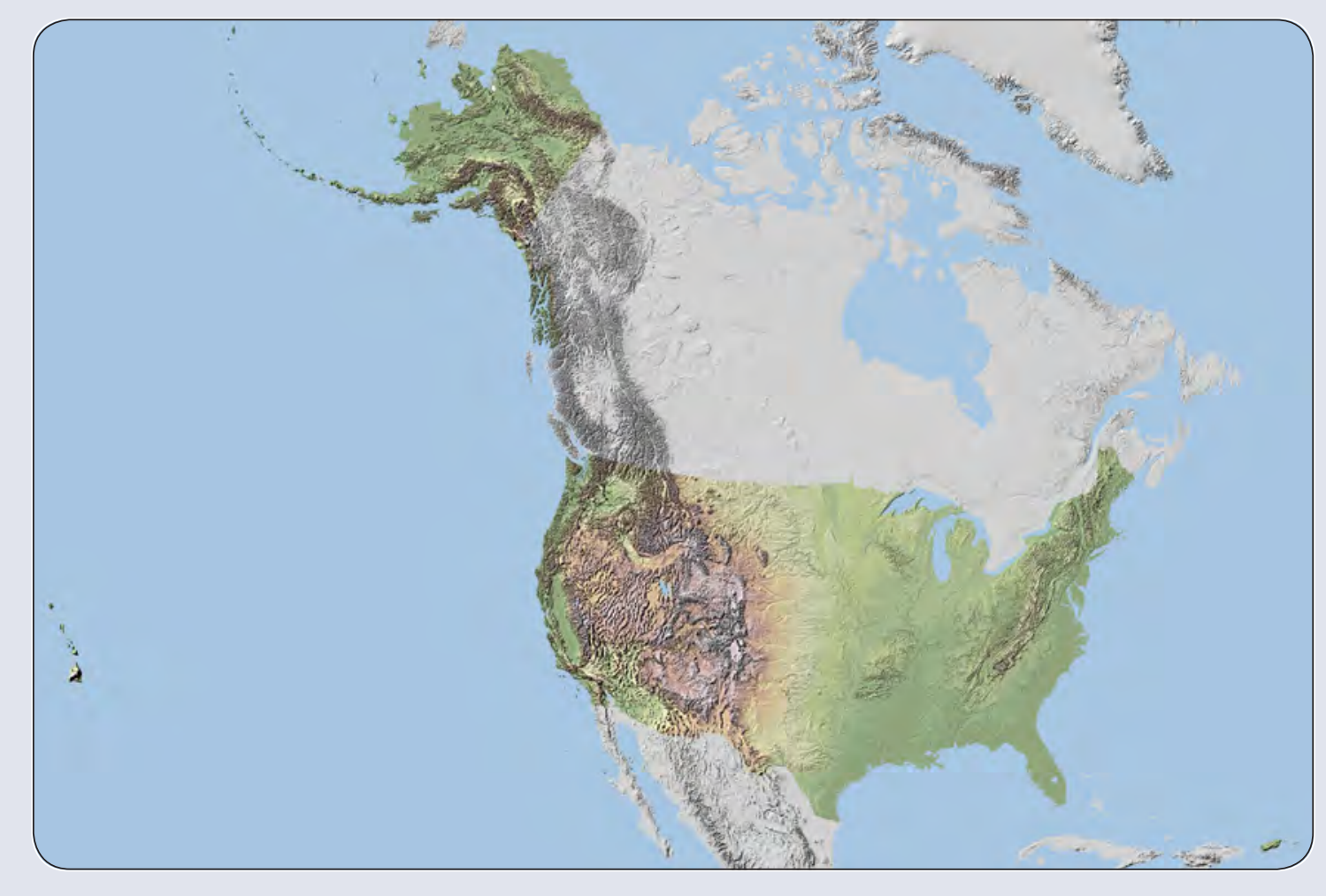

A shaded-relief representation of the National Elevation Dataset (NED) covering the United States. Elevation is portrayed as a range of colors, from dark green for low elevations to white for high elevations. 


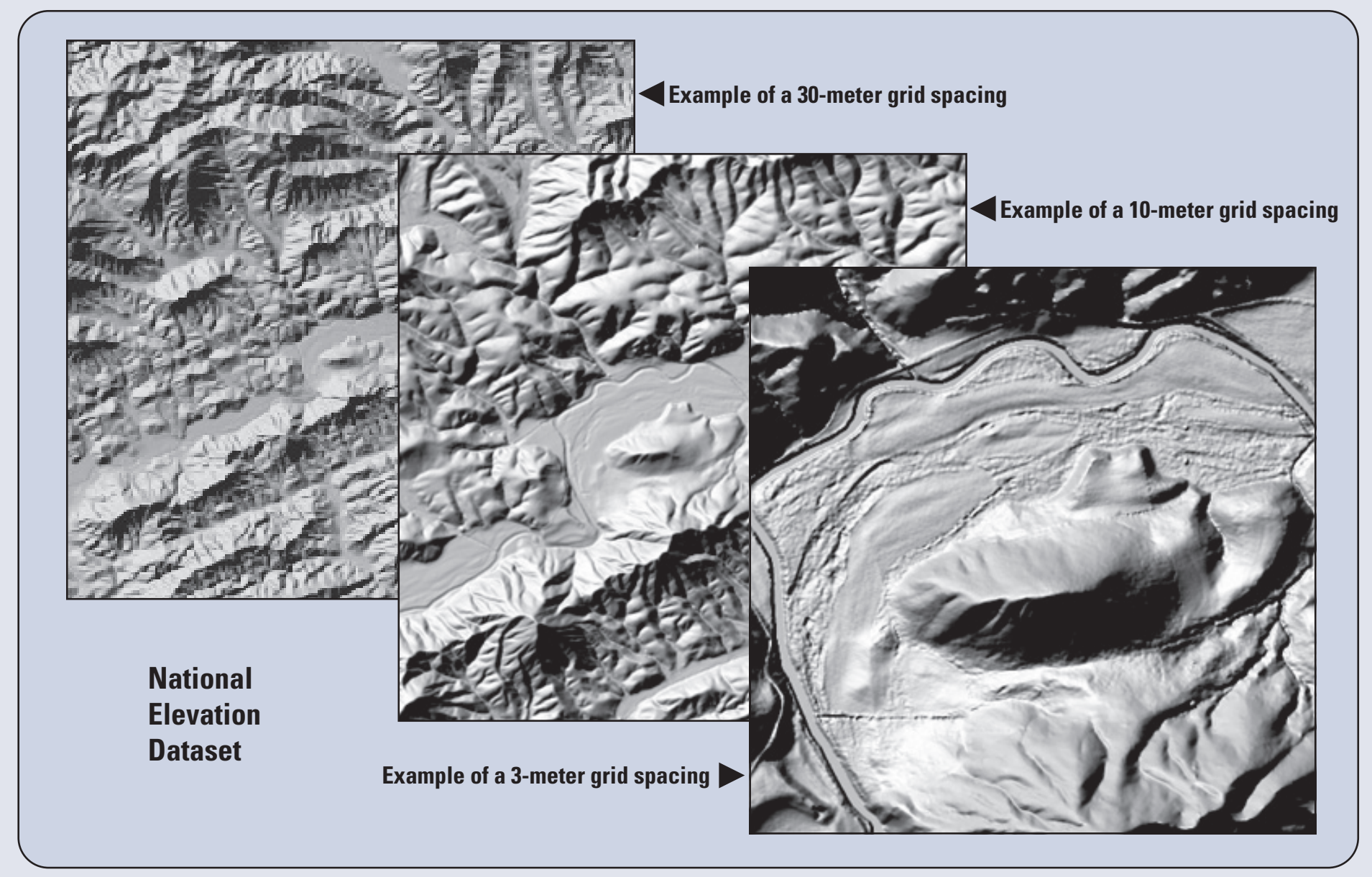

Shaded relief images of an area in North Carolina derived from the three resolutions available in the NED.

\section{Applications of Elevation Data}

Elevation data are an essential part of many earth science applications. The NED is used for such diverse purposes as:

- Providing shaded-relief backgrounds,

- Generating contours, synthetic drainage networks, or watershed delineations,

- Classifying land cover,

- Geometrically correcting remotely sensed data (orthophoto rectification),

- Deriving landform characteristics such as slope and aspect,

- Modeling applications such as hydraulic and hydrologic studies,

- Dispersion modeling,

- Predicting wildland fire behavior,

- Flash flood forecasting,

- Regional soil erosion,

- Climate data analysis,

- Vegetation height estimation,
- Air traffic safety, and

- Flight simulation and video games.

\section{Data Availability and Plans}

Elevation data are available from the NED in a seamless, nationally consistent form through the USGS The National Map Seamless Server, http://seamless.usgs.gov/ The National Map Seamless Server allows users to download, at no cost, an area of interest by drawing a box, defining coordinates, or using available templates to extract areas. These elevation data also are available through a bulk data delivery system, (email bulkdatainfo@usgs.gov for information), and in the future will be available through the Tiled Data Distribution System accessible through The National Map Seamless Server.

The NED offers multiple layers, at 1, 1/3 and 1/9 arcsecond (approximately 30, 10 and 3.3 meters, respectively). Where available, higher resolution data will replace the current NED content, providing a continually upgraded national multiresolution dataset. Higher resolution layers will be populated through the integration of data from various sources, using new technologies, and will be acquired through partnerships with Federal, State, and local partners, providing access to the best available local information. Lidar derived elevation data are the primary means currently (2009) being used to upgrade the NED. A complementary USGS activity to the NED is the Center 


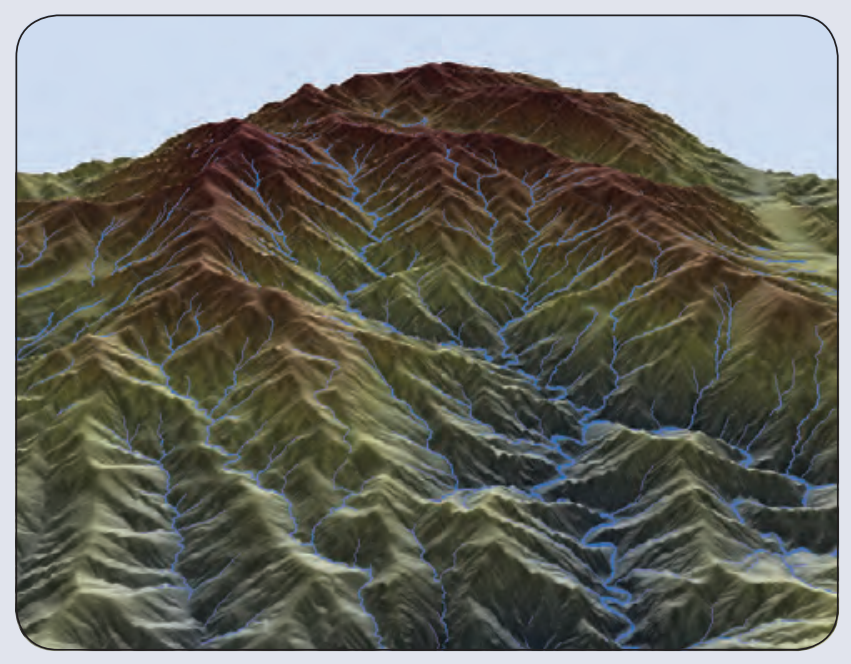

\section{Surface hydrology features in southern California derived from lidar elevation data.}

for lidar Information Coordination and Knowledge (CLICK) (http://lidar.cr.usgs.gov/). Data acquired for distribution through the CLICK also are used as a source of high-resolution bare earth elevation data to upgrade the NED. In addition, through the CLICK, users have access to the full-return point cloud form of lidar data that is included in the NED as bare earth gridded elevation data.

\section{Partnership Opportunities}

Organizations interested in partnering with the USGS to develop elevation data for The National Map should contact the USGS mapping liaison in their State. The list of liaisons is available at http://www.usgs.gov/ngpo/ngp_liaisons.html

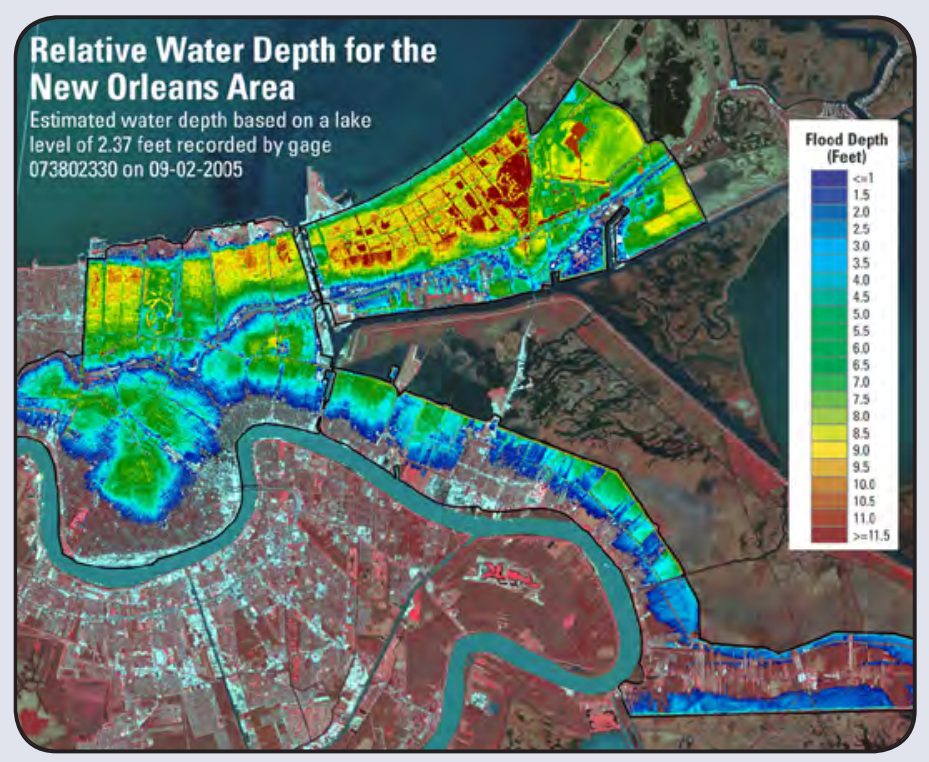

Lidar-derived bare earth elevation data aids storm response and recovery operations.

\section{The Nation Needs The National Map}

As one of the cornerstones of the U.S. Geological Survey's (USGS) National Geospatial Program, The National Map is a collaborative effort among the USGS and other Federal, State, local, and Tribal partners to improve and deliver topographic information for the Nation. The National Map has many uses ranging from recreation to scientific analysis to emergency response. The National Map is easily accessible for display on the Web, as products and services, and as downloadable data. The geographic information available from The National Map includes orthoimagery (aerial photographs), elevation, geographic names, hydrography, boundaries, transportation, structures, and land cover. Other types of geographic information can be added within the viewer or brought in with The National Map data into a Geographic Information System to create specific types of maps or map views.

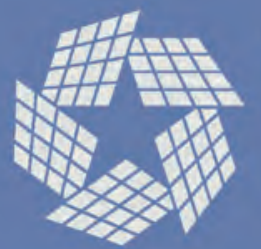

\section{The National Map}

The National Map is a significant contribution to the National Spatial Data Infrastructure (NSDI) and provides high quality, integrated geospatial data and improved products and services including new generation digital topographic maps. The National Map also is foundational to implementation of the Department of the Interior (DOI) Geospatial Modernization Blueprint and meeting the DOI mission. The National Map underpins the USGS Science Strategy, which is based on a systems approach to help address multifaceted issues, provide better understanding of earth processes, and evaluate broad causes and consequences of the use and management of natural resources. The National Map promotes interdisciplinary science by providing nationally consistent, trusted geospatial data, and establishing a consistent national geographic context. 


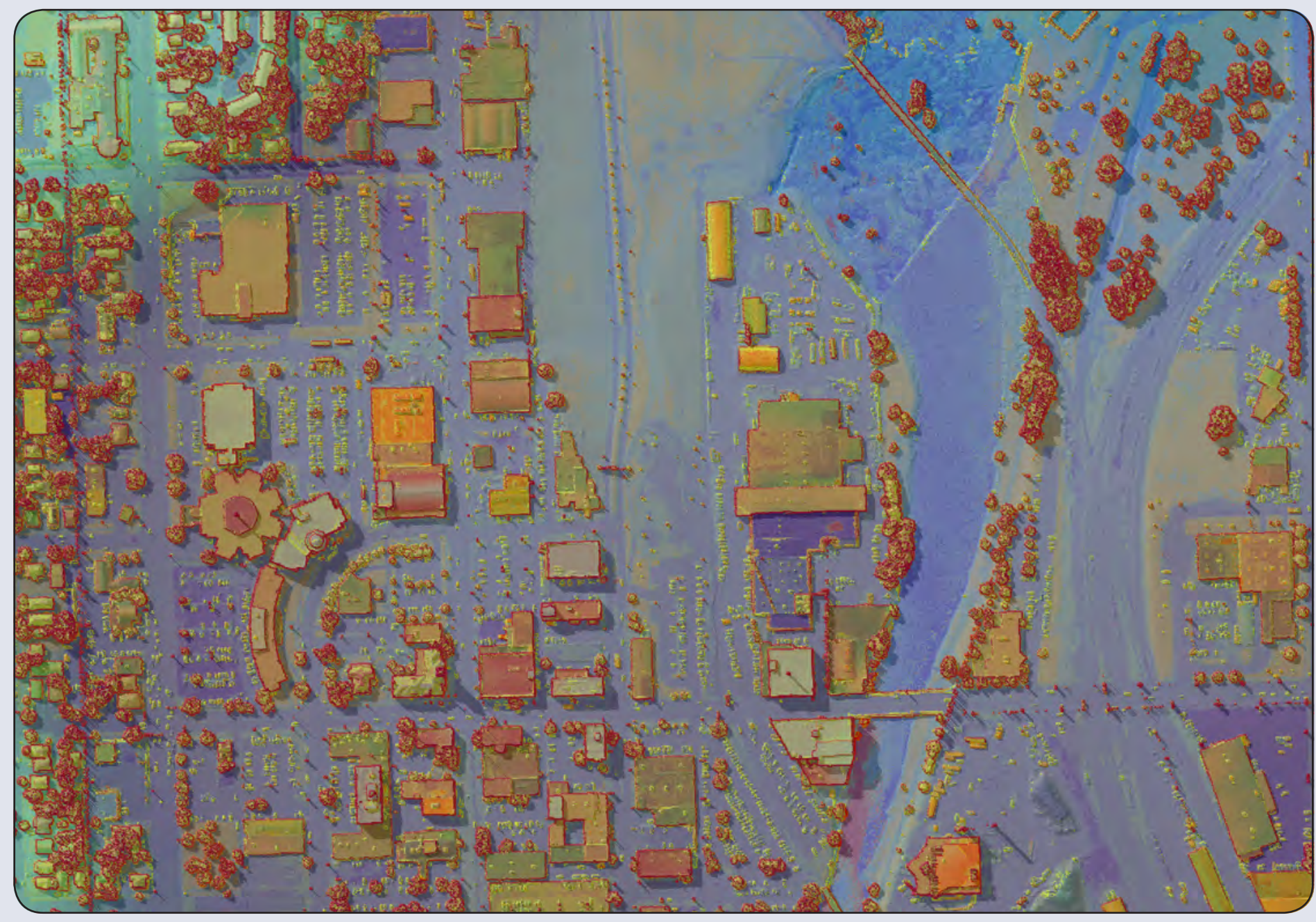

Ground surface elevation and other natural and man-made features are depicted in this lidar dataset of Sioux Falls, South Dakota.

\section{Further Information}

Further information about The National Map can be viewed or downloaded at http://nationalmap.gov/. Further information on the NED, including details on NED history, production, accuracy assessment, and applications, is available on the NED Web site (http://ned.usgs.gov/) and in the following publications:

Gesch, D.B., 2007, Chapter 4 - The national elevation dataset, in Maune, D., ed., Digital elevationl model technologies and applications: The DEM Users Manual, (2nd ed.): Bethesda, Maryland, American Society for Photogrammetry and Remote Sensing, p. 99-118.

Gesch, D., Oimoen, M., Greenlee, S., Nelson, C., Steuck, M., and Tyler, D., 2002, The national elevation dataset: Photogrammetric Engineering and Remote Sensing, v. 68, no. 1, p. 5-11.

For information on other USGS product and services, call 1-888-ASK-USGS or visit the general interest publications Web site on maps, imagery, and related publications at $h t t p: / / w w w . u s g s . g o v / p u b p r o d /$. For additional information, visit the http://ask.usgs.gov/Web site or the USGS home page at http://www.usgs.gov/.

Publishing support provided by: Rolla Publishing Service Center 